\title{
Problems of Fact, Method, Theory, and Concepts in Tsoukas (2018)
}

\author{
Anita M. McGahan ${ }^{1}$ (D)
}

Received: 22 May 2019 / Accepted: 11 February 2020 / Published online: 5 March 2020

(c) The Author(s) 2020

\begin{abstract}
On January, 27, 2017, U.S. President Donald J. Trump issued Executive Order 13769 on immigration and travel (EO 13769), which restricted entry into the U.S. of the citizens of seven primarily Muslim countries. Many academics reacted with outrage, including me and other members of the Academy of Management (AOM), of which I was President at the time. Some scholarly associations condemned EO 13769 as immoral, but the AOM did not immediately issue such a condemnation because the AOM's Constitution included a policy of no-political-stands (NPSP) and a principle that nobody, including the AOM President, could represent personal views as those of the organization. Within a few weeks, the AOM Constitution was changed, and in October, 2017, the AOM joined other associations in issuing a condemnation. An article was published in this journal on this situation (Tsoukas in J Bus Ethics, https://doi.org/10.1007/s10551-018-3979-y, 2018) that was subsequently amended through a published Correction (Tsoukas in J Bus Ethics, https://doi.org/10.1007/s10551-019-04194-9, 2019), but the Correction only partially addressed the problems in the original. The main contribution of this commentary is to take up the invitation in Tsoukas (2018) to examine the case for insights on theoretical and conceptual questions raised in the literature on prototypicality and moral imagination. It also briefly outlines the most significant omitted errors of fact in Tsoukas (2018) that were not corrected in Tsoukas (2019), and describes the most important methodological problems in Tsoukas (2018). The conclusion suggests that the complex, nuanced, and evolving interactions that unfolded at the AOM are not fully addressed theoretically or conceptually in this literature.
\end{abstract}

Keywords Ethics $\cdot$ Management $\cdot$ Organizations $\cdot$ Leadership

On December 18, 2018, I learned about an article in the Journal of Business Ethics by Haridimos Tsoukas (hereafter Tsoukas 2018) assessing my moral imagination as President of the Academy of Management (AOM). The assessment is based on a message sent to AOM members on January, 31, 2017, after US President Donald Trump's Executive Order 13769 , commonly called the "immigration and travel ban" (EO 13769, Exhibit 1). On June 24, 2019, the Journal of Business Ethics published online a Correction to Tsoukas (2018) that addressed a number of inaccuracies in the article

This comment refers to the article available online at https://doi. org/10.1007/s10551-018-3979-y.

This comment refers to the article available online at https://doi. org/10.1007/s10551-019-04194-9.

Anita M. McGahan

anita.mcgahan@rotman.utoronto.ca

1 Rotman School of Management, University of Toronto, 105 St George Street, Toronto, ON M5S3E6, Canada (hereafter Tsoukas 2019), but which did not address its most interesting problems. The purpose of this commentary is to identify opportunities to develop the methods, theory, and concepts in the literature on prototypicality and moral imagination into which Tsoukas (2018) was written. ${ }^{1}$

Tsoukas (2018) argues that EO 13769 constituted a 'non-prototypical' political event that demanded a different response than the message sent to AOM members on January 31,2017. According to the analysis, I and the other members of the AOM Executive Committee should have exercised "moral imagination" to interpret EO 13769 as a non-prototypical political event, and therefore one on which the AOM's no-political-stands policy (NPSP) should not be applied rigidly or as a recipe. Instead, the message should have inspired a deliberative response among AOM members by disclosing powerfully the meaning of EO 13769 as an immoral act. Tsoukas (2018) says that leaders such as me

\footnotetext{
1 A requirement imposed on this commentary by the Co-Editors of this journal is that it make a theoretical and/or conceptual contribution, rather than only correct the facts and discuss the methods in Tsoukas $(2018,2019)$.
} 
must make judgments about the meaning of important events such as EO 13769, and that rules such as the AOM's nopolitical-stands policy (NPSP) must not be rigidly applied when events evolve non-prototypically.

My response in this commentary unfolds in four main sections. First, I briefly describe the most important facts about what occurred at the AOM that were not covered in either the original or corrected version of Tsoukas (2018) and that are relevant to the methodological, theoretical and conceptual issues. Second, I indicate the main methodological problems in Tsoukas $(2018,2019)$. Third, I identify some of the most salient gaps in the theory in Tsoukas (2018, 2019) raised by the case of the AOM. Fourth, I raise conceptual challenges, issues, and opportunities in the literature to which Tsoukas $(2018,2019)$ contributes. The conclusion suggests that the methods, theory, and concepts in the literature on prototypicality and moral imagination are insufficiently developed to reflect the complexity of the interactions that unfold in situations such as at the AOM in 2017.

\section{Problems of Fact}

Among the many factual problems with Tsoukas (2018, 2019), there is one that is the most important. The main assumption in both the original and corrected versions of the paper is incorrect. This assumption is that the message on January 31, 2017, could have been written to enact my personal belief that EO 13769 was immoral.

This assumption fails on three grounds. First, the condemnation of EO13769 that I originally proposed three days prior to the issuance of the message was not accepted by the AOM Executive Committee because of two principles in the AOM Constitution. ${ }^{2}$ The first was a principle that the AOM would cultivate debate among AOM members holding divergent views over political events. This principle, which gave rise to the NPSP, had been interpreted to cover postWorld War II political policies, the Vietnam war, the events of September 11, 2011, climate change, LGBTQ+ rights, and immigration. The second was the tenet that nobody, including the AOM President, can express a personal view as that of the organization. As a result, the AOM Executive Director, who controlled the AOM's listservs, would not have allowed the issuance of a non-conforming message by me or by anyone out of loyalty to the AOM Executive Committee decision and AOM Constitution. In other words, governance power over crucial tools of disclosure and deliberation was not allocated to me as AOM President, but rather to the AOM Executive Committee. This allocation was in

\footnotetext{
2 The AOM Constitution is what the Board of Governors refers to as the system of By-Laws, rules, practices, and systems by which the AOM is governed.
}

direct conflict with the allocation of power to speak for the organization to the AOM President. I therefore condemned EO 13769 as immoral in my own name, but not the name of the organization.

Second, the main assumption in Tsoukas (2018) also fails through a change made in the Correction (Tsoukas 2019) to reassign responsibility for the January 31,2017 , message away from me and to the AOM Executive Committee as a whole. The problem is that the Correction does not interrogate whether the six members of that Committee all shared the belief that EO 13769 was morally wrong and non-prototypical categorically relative to the other political events to which the NPSP had been applied. This is important because the argument in Tsoukas (2018) depends on the claim that the authors of the message held a coherent, mutual interpretation of EO 13769 as morally wrong, and that this shared belief was not in conflict with other beliefs about moral obligations. In the case of EO13769, the members of the AOM Executive Committee did not immediately hold such a shared understanding, although we worked together ardently, intensively, and collaboratively — through deliberation — to discern a way forward that reflected our competing obligations.

Third, the main assumption in both the original and corrected versions of the article fails because it does not consider the three-part moral paradox that I personally confronted at the time of EO13769 both as AOM President as a member of the AOM Executive Committee (see McGahan 2017a, b, 2019). The paradox arose from my simultaneous beliefs that (a) the US President's immigration policies were racist and discriminatory, (b) the US President's tactic of attacking the construct of the truth by making false claims about immigrants and other matters was divisive, anti-scientific, and polarizing, and designed to pit intellectuals against each other, and (c) the NPSP was a Constitutional principle of the AOM that had shaped its identity and that had merit. The paradox arising from these three beliefs (explained more fully in McGahan 2019) implies for the argument in Tsoukas $(2018,2019)$ that, even though I believed that EO 13769 was immoral, I could not enact that personal belief in the January 31, 2017, message because I believed that adjudication of the NPSP was a Constitutional matter for the AOM that required due process. Furthermore, I did not believe that EO13769 was non-prototypical Constitutionally, i.e., I believed the event was within the scope of the intended policy in that it was of commensurate significance to events listed above that had shaped the emergence of the NPSP (i.e., the post-World War II political policies, Vietnam War, and so on). I also imagined that the issuance of a message reinterpreting the NPSP would harm deliberation among AOM members rather than support it. ${ }^{3}$ In other words, I

\footnotetext{
${ }^{3}$ Please see Exhibits 1 and 2 of McGahan (2019), for the text of memos that I wrote at the time of EO13769 in which I discuss this situation.
} 
sought to cultivate within the AOM the deliberations that the NPSP was designed to encourage, but I did not believe that the best way to accomplish this was through the message that Tsoukas $(2018,2019)$ analyzes. Rather, I used other tools and vehicles of communication (McGahan 2019).

There are also extensive additional factual problems in both the original and corrected versions of Tsoukas (2018), including the omission of crucial information about the timeline. A number of resources are available to readers interested in learning about what happened at the AOM before, during, and after EO 13769, including McGahan (2017a, b, 2018), the AOM.org website, and a series of articles published in the Journal of Management Inquiry in July, 2019, interpreting both the events at the AOM and Tsoukas (2018). ${ }^{4}$ One of these articles, namely Stackman et al. (2019, pp. 271-274), contains a line-by-line description of problematic statements in Tsoukas (2018).

Exhibit 2 of this paper summarizes the timeline. The top half of the exhibit describes the unfolding of events relevant to the analysis. A statement from the AOM ratifying the accuracy of this timeline appears at the end of this article. The bottom half of Exhibit 2 shows the small number of events reported in Tsoukas $(2018,2019)$.

The following five essential facts are not covered in Tsoukas (2018, 2019), and are mentioned here because they are relevant to the arguments about methods, theory, and concepts that follow:

1. As AOM Vice President, I had proposed in July of 2015, eighteen months before EO 13769, that the AOM change the NPSP out of concern about the persecution (including censorship and arrest) of scientists in Turkey and China; and because of problems that had arisen over questionable research practices, such as p-hacking, and in response to an initiative for responsible research in our field (McGahan 2019). The proposal had been discussed by the AOM Executive Committee, was sent to Board subcommittee for development, had been raised at the AOM Board meeting in December, 2016, and was returned to the Board subcommittee for further work. Because deliberations about changing the policy were under way, the responses to EO 13769 among AOM Governors, including myself, reflected both the substantive and organizational issues that had evolved over time as we wrestled with the issues.

2. AOM members were not unified on what should occur at the AOM after EO 13769 (see McGahan 2019 and Wright in Davis et al. 2019). Many members felt that, because the NPSP was an integral part of the AOM's

\footnotetext{
4 These are McGahan (2019), Stackman et al. (2019), Bartunek et al. (2019), Davis et al. (2019), and Pirson et al. (2019).
}

identity as an organization, it should not be changed. Historically, the NPSP was connected to the AOM's commitment to amplify members' individual voices on matters of public importance so as to support scholarly dialogue to resolve discord and inform public policy. Many members, including me, felt that the options available to the AOM for responding to EO 13769 were broader than only making a statement about the AOM's position.

3. I condemned EO 13769 both online and offline immediately after it happened in my own name as an immoral act, and in a number of writings that were issued prior to the message analyzed in Tsoukas $(2018,2019)$. Some of the materials that I wrote are reproduced in the Exhibits to McGahan (2019). I also began an extensive process of interacting with members because I sought the two-way exchange and dialogue described in Rasche (2019). ${ }^{5}$ As described in Exhibit 2, I interacted during the Winter and Spring of 2017 with approximately 10,000 AOM members through an estimated 870 voice-to-voice calls, 5000 e-mails and social media exchanges, and 50 meetings and presentations. One of these interactions was a Facebook exchange reproduced as Exhibit 3 that is reproduced in part in Tsoukas (2018). In other words, I sought to inspire disclosively the deliberation that the NPSP had been designed to encourage through ongoing, evolving conversations rather than through the message sent to members on January 31, 2017. I also made regular reports to the AOM membership on the AOM. org website through a link on the landing page called "President's FAQs" created for this purpose. None of this communication is considered in either the original or corrected versions of Tsoukas (2018).

4. The AOM Board of Governors formally changed the Constitution of the organization to allow an exception to the NPSP two weeks to the day after EO 13769, which was the earliest possible date that such a change could

\footnotetext{
${ }^{5}$ I described these discussions to Professor Rasche in a meeting that we had at Copenhagen Business School, where he is appointed, on June 19, 2019. I explained that a few of the discussions were in-person meetings that I had with AOM members who had suggested that I should be subjected to violence, and one was with a member who had written online that I should be killed. I told Professor Rasche that I did not believe that the threats against me were serious, which is why I did not pursue their prosecution. Rather, I felt that they were expressions among some AOM members of frustration and hopelessness over EO13769 and, more generally, the emergence of nationalistic populism in the U.S. and elsewhere. In the JMI series, Professor Bell in Bartunek et al. (2019) conjectures that the outrage in the Critical Management Studies (CMS) Division of the AOM reflected the "projection of anxiety and helpless onto a (female) leader" (p. 278). I am not a scholar of such issues, and thus am not qualified to assess was what happened in these terms, but I did mention these points to Professor Rasche during our meeting.
} 
have occurred (see Exhibit 2). I called this meeting on Sunday, January 29th, 2017 (i.e., before the message that Tsoukas 2018, analyzes), for February 10th, 2017. This out-of-cycle meeting was without precedent in the seventy-five-year history of the AOM. McGahan (2019) describes in detail a series of specific steps that I took in the days right after EO 13769. The revision of the NPSP approved by the Board was accompanied by a 90 -day moratorium to provide time for a special task force to examine how the new policy would be implemented. ${ }^{6}$ One critical development that influenced the decision to impose the moratorium was that the US Courts had issued a stay on EO 13769, which meant that it was not adopted as the policy of the U.S.

5. When the moratorium expired on May 10, 2017, a process was in place that could have led the AOM to issue a condemnation of U.S. immigration policies. This process was designed to be activated when a member-atlarge of the AOM initiated a proposal to take a stand. Nobody made such a proposal until September, 25, 2017. On that date, which was a month after my term as AOM President ended, I was the member-at-large who took this step and, till now, I remain the only AOM member who has ever initiated the Board process to condemn the U.S. immigration policies under President Trump.

These and other relevant facts are described more fully in the papers and documents cited above. They are omitted from both the original and corrected versions of Tsoukas (2018).

\footnotetext{
${ }^{6}$ To support this examination, the task force was provided with a Charge Memo that I wrote in which I described the threat to the AOM arising from EO13769 in moral terms (McGahan 2019, Exhibit 1). It was also given many other documents, including those generated by the NPSP subcommittee. A survey of members was conducted, with input sent directly to the task force. The nine-person task force concluded its work with a report to the Board in April, 2017. One of the members of this task force was a professor who, in February 2018, represented himself in an e-mail to me as the initial handling editor at the Journal of Business Ethics of Tsoukas (2018) and who asked me to write a commentary without attaching a copy of the manuscript. He described it as an interesting discussion of the AOM's policy. No mention was made that Tsoukas (2018) was about me personally. When I replied by saying that any commentary about AOM policy would have to be written by the then-AOM President (on the principle that nobody but the current President can speak for the organization), this professor responded that he would contact her, but my successor as President reports that he did not. In my short reply to him, I also indicated that he had a conflict-of-interest in serving as editor of any such paper after having served on the task force.
}

\section{Problems of Method}

The methods in Tsoukas $(2018,2019)$ are inadequate to analyze the case of the AOM's response to EO 13769. A scientifically valid assessment of a person's character, including especially of a moral quality that is inherently difficult to observe, cannot be conducted effectively without the deployment of sophisticated psychological, ethnographic, social psychological, and other established methods. There should be no shortcuts when an evaluation of a person's morality is scientifically assessed.

The first major methodological problem in Tsoukas $(2018,2019)$ is the oversimplification of a complex moral problem with many facets, many constituents, diverse beliefs, and a long timeline (McGahan 2019; Exhibit 2). Tsoukas (2018) does not consider organizational processes, competing moral imperatives, or the discussion that began more than a year earlier about the persecution of scientists and the revision of the NPSP. The analysis also focuses on only one message among more than ten thousand communications. It does not consider the varying audiences and purposes of each of these interactions, or the ways in which they were interrelated and evolved.

Second, the method put forth in Yanow and Tsoukas (2009) and used in Tsoukas (2018) is not robust in its approach to inference. It is epistemologically impossible to infer beliefs from behavior, ${ }^{7}$ and equally impossible to infer from an organizational action what a single leader or small group of leaders imagines-morally or otherwise. The approach does not acknowledge that the very subject at hand - namely the AOM's response as an organization-was developed organizationally and was governed by the AOM's Constitution rather than exclusively by my choices, beliefs, and understandings as President.

A third problem of methods in Tsoukas (2018) is in the assertion that a leader's first writing after an event such as EO 13769 reflects her native understandings as a spontaneous response. But the response was anything but spontaneous because the event had been anticipated eighteen months earlier, and interpretation of the NPSP had been on the agenda of the AOM Executive Committee and the AOM Board. This makes the seminal communication difficult to identify. Was it the initial proposal, which was put forth in 2015 out of concern for vulnerable AOM members in Turkey and China? Was it the subcommittee report on changing the NPSP delivered in December, 2016, a month before EO 13769, with recommendations that were deliberated but not adopted? Was it my initial proposal for condemnation immediately after EO 13769 in January, 2017, that was not acceptable to the Executive Committee? Or my

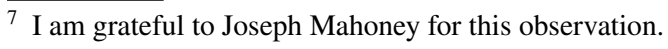


personal condemnation of EO 13769 as immoral, which was posted online? What about the phone calls and meetings that occurred between me and members of the Executive Committee? All of these occurred prior to the message analyzed in Tsoukas (2018) and Tsoukas (2019). ${ }^{8}$ In general, the first thing that a leader or group of leaders writes may not be spontaneous, may not be on the topic, may have relevant precedent, may not be observable, and/or may be deliberative rather than declarative. In this case at the AOM, the analyzed message was designed as only one of many that unfolded over time.

Fourth, the method used in Tsoukas (2018) rejects readily available, disconfirming evidence and alternative explanations about what occurred. McGahan (2019) includes the texts of other message and official memos written both before and after the message analyzed in Tsoukas (2018) and describes the nature of my communication with members after EO 13769. Neither the original nor corrected article refers to my AOM Presidential address on the AOM's response to EO 13769 (McGahan 2017c, available at https:// www.youtube.com/watch?v=Z4OldjLZTp8), and McGahan 2018, which was published months prior to Tsoukas 2018). Similarly, the deliberations among the AOM Board members about revising the NPSP, which were reported in the Board minutes and thus available to members, were not considered.

Fifth, neither consent nor research ethics approval was obtained by the author or required by the journal prior to the publication of Tsoukas (2018). ${ }^{9}$ These processes are especially important when a peer-reviewed journal seeks to publish a scientific assessment of a person's moral qualities rather than publishing, say, an expert's opinion about a matter within the person's domain of expertise. The risks of mistakes warranting a published Correction (Tsoukas 2019) are

\footnotetext{
8 Another problem with the method described in Yanow and Tsoukas (2009) and used in Tsoukas (2018) is that the first communications after an important event may be oral instead of written, and/or that it may be about a different matter than the event. The correction redirects responsibility for the message to all six members of the Executive Committee, but does not deal with the fact that the message was not the first written responses of any of the six members either individually or as a group.

9 An argument has been made that consent and research ethics review and approval were not required for assessing my moral imagination because I am a public figure. I believe that this conclusion is wrong. The AOM is a privately incorporated charitable and educational body in the state of New York, which imposes duties of care, loyalty and fiduciary responsibility onto those hold offices such as the one that I held in 2016-2017. In particular, the President is required to conform without fail to the organization's Constitution. Election into the AOM presidency is by members, not the general public, i.e., similarly to the election of the managing director of a law or consulting firm. I believe that consent and research ethics review and approval were warranted in this case just as they would be for study of the moral character of any executive of any incorporated entity.
}

reason alone to pursue customary research ethics approval when the subject is a person's morality.

Sixth, the analysis is a scientific assessment of the moral qualities of the leader(s) of an organization to which the scientist belongs. The implications of this formal organizational relationship between the scientist and the leader are not interrogated in the article. Should peer-reviewed journals publish assessments by members of organizations of the moral qualities of their organization's leaders without considering the relationship? Should this occur without consent or consultation or research ethics review? I believe the answers to these questions should be "no."

Finally, Tsoukas (2018) sets the dangerous precedent of evaluating scientifically a person's morality from identifiable, personal Facebook posts under the protections of peer review but without research ethics approval. Furthermore, my posts (Exhibit 3 ) were published publicly by Tsoukas (2018) without consent under a Creative Commons license held by Professor Tsoukas. After Cambridge Analytica and other Facebook tragedies, including those that occurred during the 2016 U.S. Presidential election, no journal should allow such a study to be published without consent and research ethics review and approval.

\section{Problems of Theory}

In this section, I briefly describe several types of theoretical problems in the argument underlying Tsoukas (2018), and the opportunities that these problems create for scholarship. To accomplish this, I rely on insights arising from the AOM case study. I conclude that the contribution to theory in Tsoukas (2018) builds on an architecture of theory that is flawed.

The theoretical literature into which Tsoukas (2018) was written developed over the past half-century to address the moral obligations of leaders in the face of extraordinary political events that are described as non-prototypical. The core of the contribution to theory is an elucidation of Johnson's (1993) construct of "moral imagination," which is described qualitatively through citations to Arendt (1982, 2003), Caputo (1997, 2000, 2004), Derrida (1996, 1997, 2002a, b), Nussbaum (1999), Selznick (1984, 1992), and others. Specifically, Derrida (2002a, b) suggests that leaders have moral imagination when they interpret issues and events using the values and purpose that gave rise to the rules and principles of the organization. When an event is non-prototypical, so goes the argument, the rules and principles must be imaginatively interpreted rather than rigidly and bureaucratically applied, because such a reinterpretation is essential to initiate deliberation over an appropriate organizational response. 
The first problem is that the basic constructs of the theory lack fidelity, by which I mean that the representation in the theory of the event, of the organization's principles, and of the leader's avenues for the expression of imagination are inexact and over-simplified and, thus, do not do justice to the ways in which both an event and the response to it develops. For example, at the AOM, the processes by which the AOM Executive Committee sought to develop a mutually held understanding of the moral issues raised by EO 13769 are not considered. The event of the issuance of EO 13769 was not independent of prior events, including especially the election two months earlier of President Trump, and the enactment of policies in other countries analogous to EO 13769. The achievement of mutual understanding across members of the AOM Executive Committee on how to resolve the competing moral claims is not theorized. The theory does not recognize that the synthesized position of the AOM Executive Committee that constituted the collective's moral imagination was developed deliberatively, i.e., it does not consider that deliberation led to the synthetic moral imagination, not the other way around. The theory has no lens on the imaginative work done to address the tensions between competing moral claims raised by EO $13769 .{ }^{10}$ In other words, the AOM case suggests that construct validity is problematic in the theory because, in at least this instance, the deliberative discourse is intertwined with imaginative processes and the event itself.

Second, the theory assumes without nuance that the problem faced by a leader is to enact deliberation once a non-prototypical event occurs. There is no consideration that deliberation may already be under way, as it was at the $\mathrm{AOM}$ and as is almost inevitable given the ubiquity of social media. There is also no contingency in the theory to account for questions about which leaders within the organization have the authority to respond on behalf of the organization. The theory does not discern between a response by a leader in the name of the organization and a response by a leader in the leader's own name. There is no reflection in the theory on the deliberations required between leaders to discern the non-prototypicality of an event. The theory is not moderated by organizational processes, discussions, and governance decisions. For example, there is no contingency in the theory that reflects that the problem at the AOM was not one of stimulating deliberation among members, but rather one of achieving constructive dialogue among members who were not aligned in their views about the relationships between

\footnotetext{
10 The communications that occurred, some of which were written, and some of which are available in McGahan (2019), illustrate this work. See also Bell and deGama (2019), which describes what occurred in the Critical Management Studies Division of the AOM. This paper also contains several errors about what occurred at the AOM.
}

EO 13769 and the organizational principles and rules of the AOM (rather than of the meaning of EO 13769). The theory does not consider that a political event such as EO 13769 may immediately stimulate deliberations among members of an organization without leadership intervention, which thus changes the challenge for the leader from one of inciting deliberation to one of understanding, shaping, and organizing deliberation. It also does not consider that some acts construed as deliberative may be morally objectionable, such as when threats of violence arise, as they did at the AOM.

The third is that the constructs are mutually determined. The quality of deliberation already under way may influence the nature of the decision to which moral imagination is construed as relevant; and the event (prototypical or not) may be designed to disrupt organizational processes. For example, in 2016, I interpreted the US President's attacks on the truth itself as designed instrumentally to foment discord among scholars. The communications in which I engaged, including the message analyzed in Tsoukas (2018), were part of a much broader set of interactions between me and members in which I sought to encourage, support, and cultivate the AOM's purpose of constructive dialogue toward the resolution of important social problems. The plan of communication itself into which the message was embedded co-evolved and reflected emerging information about both the U.S. President's immigration policies and the nature of the U.S. President's communications online and offline. In other words, the conversations among members of the AOM, and between me as AOM President and those members, were part of the meta-events of which EO 13769 was a part. The theory employed in Tsoukas $(2018,2019)$ does not consider this.

The fourth is that direction of causality in the relationships between the constructs is incorrectly stipulated for at least the category of situations into which the AOM falls. At the AOM, the relationship between the NPSP and the vulnerability of scholars that preceded EO 13769 (i.e., in Turkey and China) had an important impact on the plan of communication crafted by the AOM Executive Committee and Board of which the analyzed message was a part. ${ }^{11}$ Thus, deliberations had co-evolved with policies that employed tactics that were also engaged in the issuance of EO 13769.

Fifth, the theory is not clear on any robust approachimaginative, deliberative, or otherwise-for discerning between politically prototypical and non-prototypical categories of events. Because judgment is required, reasonable and morally imaginative actors may disagree. At the

\footnotetext{
11 AOM Governors had determined that the response was a matter of principle and would not involve a calculation as to how many members were affected. The deliberations were about the AOM's mission, values, and identity.
} 
AOM, the events that were in the politically prototypical category to which the NPSP applied included post-World War II policies for European and Japanese reconstruction; the Vietnam War and the anti-war protests of the 1960s, including those of Students for a Democratic Society, and the events of September 11, 2001 and the USA-Iraq war, and others. The AOM Executive Committee determined that EO 13769 was covered by the NPSP, which according to the theory, is aligned with the judgment that the event was politically prototypical rather than non-prototypical. This determination reflected the reason for the founding of the AOM in the 1930s, which was to provide a community that worked differently from other disciplinary associations that did make political statements.

In my role at the AOM, I personally believed in the merit of in the NPSP's purpose, which was to cultivate civil dialogue among AOM members on matters of importance, but I did not believe that the prototypical categorization of such events that had given rise to the NPSP was sufficient given the evolution of such issues. This is why I had proposed in 2015 that the NPSP be modified. In other words, I sought to engage in a profoundly political process within the AOM of seeking to change the principles-and, by extension, the prototypicality of the categories defined by them-enacted in the NPSP. I believed that the political events within the categories had changed even though the categories themselves had not (i.e., I saw EO 13769 as prototypically political, but the nature of the prototypicality as evolving in ways that I felt threatened science and scientists). In the absence of a nuanced treatment of these compounded and complicated problems of the discernment of both prototypicality and categories, the theory leaves to the adjudicating scientist an assessment of the judgment of the leader in understanding them. As a consequence, the theory fails, for it simplifies the assessment to one of a judgment made by the scientist of the leader without considering whether the leader may be engaged in a deeply political and lengthy process of changing understanding of the categories themselves.

Finally, the theory offers no criteria for distinguishing the following situations: (a) a leader views rules narrowly and bureaucratically, without recognizing the need for their reinterpretation under changing conditions; (b) a leader views the category of an event as prototypical of those that have shaped the interpretation of a rule, but sees the categorizations implicit in the rule as inadequate to support the purpose of the rule, and thus the rule as requiring reconstitution, but is overruled in implementing the view unilaterally by a governance body with an equally legitimate mandate to conduct an interpretation; at the same time, both the leader and other governance bodies see moral imperatives emanating from an event as multi-faceted and paradoxical, and thus requiring a complex resolution that deals powerfully with relationships between these moral imperatives. At the AOM, situation (b) prevailed, and thus provides at least one case that demonstrates that the theory is insufficiently developed, for it does not consider a more complex organizational political dynamic that may break a link between a leader's views and the organization's response. The principles at work in such a situation are effects, and this means that there must always be an interpretative, deliberative process in deciding under which conditions it might be appropriate to alter the rules (or even to figure out what the rules mean here and now). At the AOM, the figuring out of what the NPSP meant occurred prior to, during, and after the issuance of the message that Tsoukas (2018) analyzes, in a process that was deeply and dynamically complex both organizationally and politically, and that was equally complex in its interaction with the evolution of the very event that the theory takes as conferred exogenously.

The contribution to theory claimed by Tsoukas (2018) is a judgment about whether, at the AOM, an imaginative reframing occurred. Tsoukas (2018) does not consider that organizations have missions, visions, and values that are enacted in their governance arrangements, and that an organizational leader's charge is, among other things, to lead members who may differ in their beliefs. The suggestion in Tsoukas (2018) that I should have violated the AOM Constitution runs squarely against the purpose of the checks and balances of governance that the AOM had adopted. The six theoretical problems outlined here suggest that, because of a confounding of constructs, absent contingencies, incorrect level of analysis, inadequate treatment of organizational actors, absent treatment of interactions between organizational actors, and incorrect representations of categories and of interpretation of those categories, the theory is inadequate to address these complexities.

Tsoukas (2018) also seeks to discern a boundary between two types of moral imagination, namely disclosive power and incremental force, without stipulating the theoretical conditions that would give rise to either type, and without identifying the ways in which the constructs of power and force are attributes of imagination itself. Further, these constructs are not linked to the nuanced and complex interrelationships between organizational leaders, each with authority and responsibility for implementing conflicting principles, in interpreting and understanding the meaning of events surrounding the organization. With no discussion of construct validity, and no criteria linking the constructs through the organization to the meaningful actions taken by the organization's leaders, the contribution is not theoretically robust. 


\section{Conceptual Problems}

This section points to three broad conceptual problems in the literature on which Tsoukas (2018) rests. The first is that the theory incorporates a prototypical, industrial-era conceptualization of organizational leadership and deliberation that is insufficient for supporting analysis of the moral imperatives that leaders face in non-hierarchical organizations with complex governance structures. The second is that theory does not deal with the emergence of new types of political events that are specifically and instrumentally taken to challenge legitimacy of the totality of the principles that gave rise to an organization. The third is that the theory divorces the responsibilities of the leader from the veracity and character of the leader's beliefs about morality. In this section, I briefly review each of these issues.

The first conceptual challenge relates to the lack of adaptation of core constructs and stipulated relationships to twenty-first-century organizations, communication processes, and leadership imperatives. For example, at the AOM, members deliberated over EO 13769 intensively and continuously through social media, web platforms, blogs, e-mail, and other systems. The creation of meaning and the interpretation of events are not primarily vested in the leader, but rather constitute an emergent and evolving event of its own, such as at the AOM immediately after EO 13769. But the theory does not consider that what may be nonprototypical is the character and quality of the deliberations among members (e.g., as incivil). Similarly, the nature of the AOM as an organization had evolved significantly over the years since its founding to reshape the relative authority and responsibilities of its governance bodies, including the Divisions and Interest Group leaders, the AOM Executive Committee, the AOM Board, and the AOM President. By the time of EO 13769, many rules and principles had accumulated to interact with the NPSP and the restrictions on presidential voice. Yet the theory does not consider these evolutions or interactions.

The second is that the theory does not deal with situations in which a leader believes that the seminal event that gives rise to the need for reinterpretation is designed specifically to evoke that reinterpretation. In other words, in the current era of ubiquitous news cycles, constant surveillance, and mechanisms of digital deliberation, one type of political act is to use these mechanisms of communication to disrupt the activities of organizations that would resist their cooption. The theory takes no perspective on itself by not offering boundary conditions on its application.

Third, the theory does not consider the substance of the leader's beliefs about what is moral and immoral, which can lead to a perverse assessment through its application of the quality and character of a leader's response. Zenger in Davis et al. (2019) points to a profound irony in Tsoukas (2018): "After all, the executive order that prompted this moral dilemma for the Academy of Management's leadership was precipitated by a leader who in pursuit of a 'moral agenda' that the vast majority of AOM membership presumably viewed as abhorrent, exercised precisely such 'moral imagination,' viewing US laws not as rules, but rather as 'reminders,' at best" (Zenger in Davis et al. 2019). By resting the assessment of the morality of the leader on the link between the leader's imagination and action, the theory distances itself from the nature of the moral problem that gives rise to the imaginative act. The morality of the beliefs of the leader in situ cannot be set aside in the assessment. Similarly, the morality of the beliefs of the scientist about the event must be interrogated.

Each of these problems points to opportunities for further scholarship. Additional theorizing is needed to understand the relationships between digital deliberation and the evolution of principles of organization under non-prototypical and even prototypical political events. The instrumental evocation of organizational crisis through non-prototypical political acts must be considered. And the theory must be developed to consider how the substance and character of the moral beliefs of a leader stand up in light of the organization's principles.

\section{Conclusion}

This paper points to problems of fact, methods, theory, and concepts in Tsoukas (2018) to demonstrate that the literature on prototypicality and moral imagination are insufficiently developed to reflect the complexity of the interactions that unfold in situations such as at the AOM in 2017. At the AOM, the message analyzed in Tsoukas (2018) responded to deliberations that were already under way, and was one among more than ten thousand interactions that I had with members through a wide range of media: e-mails, web posts, presentations, phone calls, in-person meetings, Committee meetings, conference calls, and task force charges, among others. I interacted with members in these ways because I was committed to strengthening the AOM as an institution of science through scholarly dialogue, which was the principle behind the NPSP that I sought to support, and that I felt was threatened by EO 13769. I wanted the scholars of the AOM to deploy their best and distinctive capabilities to demonstrate the social consequences of the weaponization of falsehoods as truths, and of the immoral and racist policies deployed in the U.S. against vulnerable immigrants. The AOM's members are uniquely capable of contributing to public understanding of what is happening in the world around us. A condition of the AOM mission is that scholarly dialogue is not only possible, but that it is the most 
constructive and significant way in which scholars can remediate social divisions (Adler in Stackman et al. 2019; Bartunek in Pirson et al. 2019; Pirson in Pirson et al. 2019; Philips in Pirson et al. 2019; Ozkazanc-Pan and Donnelly in Davis et al. 2019; Rasche in Davis et al. 2019; Tsui in Davis et al. 2019; McGahan 2017a, b, 2018, 2019).

We make important choices in moments like this. Stackman and Martin de Holan in Stackman et al. (2019) invite us to 'renounce aggression' in the face of policies such as EO 13769, and instead to engage in civil scholarly dialogue. All of us-as scholars-have an opportunity to recognize, embody, and enliven our roles in protecting the truth in society, whatever we believe that truth to be. Whether purposefully or not, if we use the tools of our profession to represent falsehoods as if they are true, then we discredit our profession, reduce the standing of our journals, erode the foundations of scholarly association, legitimize divisiveness, and harm those we could have helped. My moral imagination over EO 13769 was that we could deploy our best capabilities to pursue rigorous scholarship with humanity, compassion, and integrity, which is what the AOM's NPSP was designed to encourage. What had changed was the moral character of prototypical political events and the nature and timeline of deliberation. The theory and concepts employed in the literature on which both the original and corrected versions of Tsoukas (2018) relies do not account for these changes or the challenges that they create. Therefore, I call for scholarship on them as I did in the message that Tsoukas (2018) analyzes (see Exhibit 1).

Acknowledgements I am grateful to many colleagues for comments, support, and suggestions and also thank the special editor and three anonymous referees.

\section{Compliance with Ethical Standards}

Ethical Approval The University of Toronto's Research Ethics Board Manager in the Social Sciences and Humanities has provided an official determination letter that this activity is exempt from research ethics review under Canada's federal research ethics guidelines, the Tri-council policy statement on Ethical conduct for research involving humans, 2nd Edition (TCPS-2), Article 2.1, and the University of Toronto's Principles to determine exemption from research ethics review. This essay is an opinion and an invited Commentary on Tsoukas (2018), which is an analysis of my beliefs, actions, moral imagination, moral character, message of January 31, 2017, and two Facebook posts, one of which was my personal condemnation of EO13769 and the other of which described work to change the NPSP. The research reported in Tsoukas (2018) was conducted without my consent or knowledge, and, I have been told, without review or approval of an Institutional Review Board.

The 2018-2019 President of the Academy of Management, Professor Carol Kulik, has provided the following statement: "Speaking on behalf of AOM, we do not believe that you need our consent to publish the commentary. The commentary presents a timeline of events that aligns with our records, and describes your perspective and behaviors while those events were taking place. We have no objection to this; you are proceeding with the commentary with our consent."

Open Access This article is licensed under a Creative Commons Attribution 4.0 International License, which permits use, sharing, adaptation, distribution and reproduction in any medium or format, as long as you give appropriate credit to the original author(s) and the source, provide a link to the Creative Commons licence, and indicate if changes were made. The images or other third party material in this article are included in the article's Creative Commons licence, unless indicated otherwise in a credit line to the material. If material is not included in the article's Creative Commons licence and your intended use is not permitted by statutory regulation or exceeds the permitted use, you will need to obtain permission directly from the copyright holder. To view a copy of this licence, visit http://creativecommons.org/licenses/by/4.0/. 


\section{Appendix}

\section{Exhibit 1: Message sent by McGahan via an internal listserv to the AOM Membership on January 31, 2017}

Dear friends and colleagues in the Academy of Management: I'm writing to you today as President of the AOM in the wake of the Executive Order signed by President Trump to suspend entry into the United States of citizens from Iran, Iraq, Libya, Somalia, Sudan, Syria, and Yemen.

Thank you to those who have written to me and to other officers about the new restrictions on travel and their implications for AOM. Thanks as well to those of you who have posted on listservs and social media. The scores of messages that I have read reflect the diversity of our 20,000 members, and of the political, social, and cultural traditions of the 127 nations where we live and work. Our members hold a range of views on the public policies that have recently been implemented. Many of you have expressed concern about travel to the Annual Meeting in Atlanta; many are interpreting the Executive Order as a direct attack on scholarship; and some are worried about the implication for pluralism on all sides of this issue. A number of you have asked the AOM to condemn the order as antithetical to scholarly values, academic freedom, and democratic processes. Yet because of our very diversity, the AOM has long had a binding policy that restricts any officer from taking a stand on any political issue in the name of the AOM.

I can affirm as President that the AOM stands behinds its vision, mission, objectives, and core values. The AOM fervently values all its members. We are committed to inclusion, supportive communities, and social and academic freedom as fundamental and undeniable tenets of scholarly association. Our values emphasize the full diversity of member backgrounds and experiences. The AOM Statement of Values expresses that "We respect each of our members' voices and seek to amplify their ideas." To enact our values, we are taking initiatives on several fronts. First, the $\mathrm{AOM}$ is suspending the requirement of attendance as a condition of inclusion in the program at the Annual Meeting for those affected by the travel restrictions. All scholars whose work is accepted to the conference but are not able to enter the United States from travel-restricted countries will have access to sessions in which they are presenting through virtual means. Second, we will also share with you, via our website, the best information that we have about Visa application processes for those who want to attend. We encourage any member from the affected countries who wishes to attend but cannot because of travel restrictions to contact us so that we can work with you toward participation.

Our mission is "To build a vibrant and supportive community of scholars by markedly expanding opportunities to connect and explore ideas." To fulfill this mission, the AOM will soon hold specialized conferences outside the United States on topics proposed by and of interest to members. Please see our website for information on this initiative. I invite you to submit a proposal if you are interested in leading one. We also will continue working with our affiliates and associates around the world who convene meetings in support of management scholarship and teaching.

The vision of the AOM is to inspire and enable a better world through our scholarship and teaching about management and organizations. I encourage AOM members to double down on the scholarly agenda. Let us be more engaged, creative, and committed to scholarship and teaching on the issues of our day. Let us stand together in Atlanta in solidarity with our diverse membership as the world's premiere association of management scholars and business-school professors. Academic integrity is our strength. Through our scholarly discussions and debate, we can find a way forward together. This is the AOM's purpose and this cannot and will not change.

Thank you again for your involvement in our AOM community, for your ideas, and for your work as educators.

Sincerely,

Anita M McGahan 


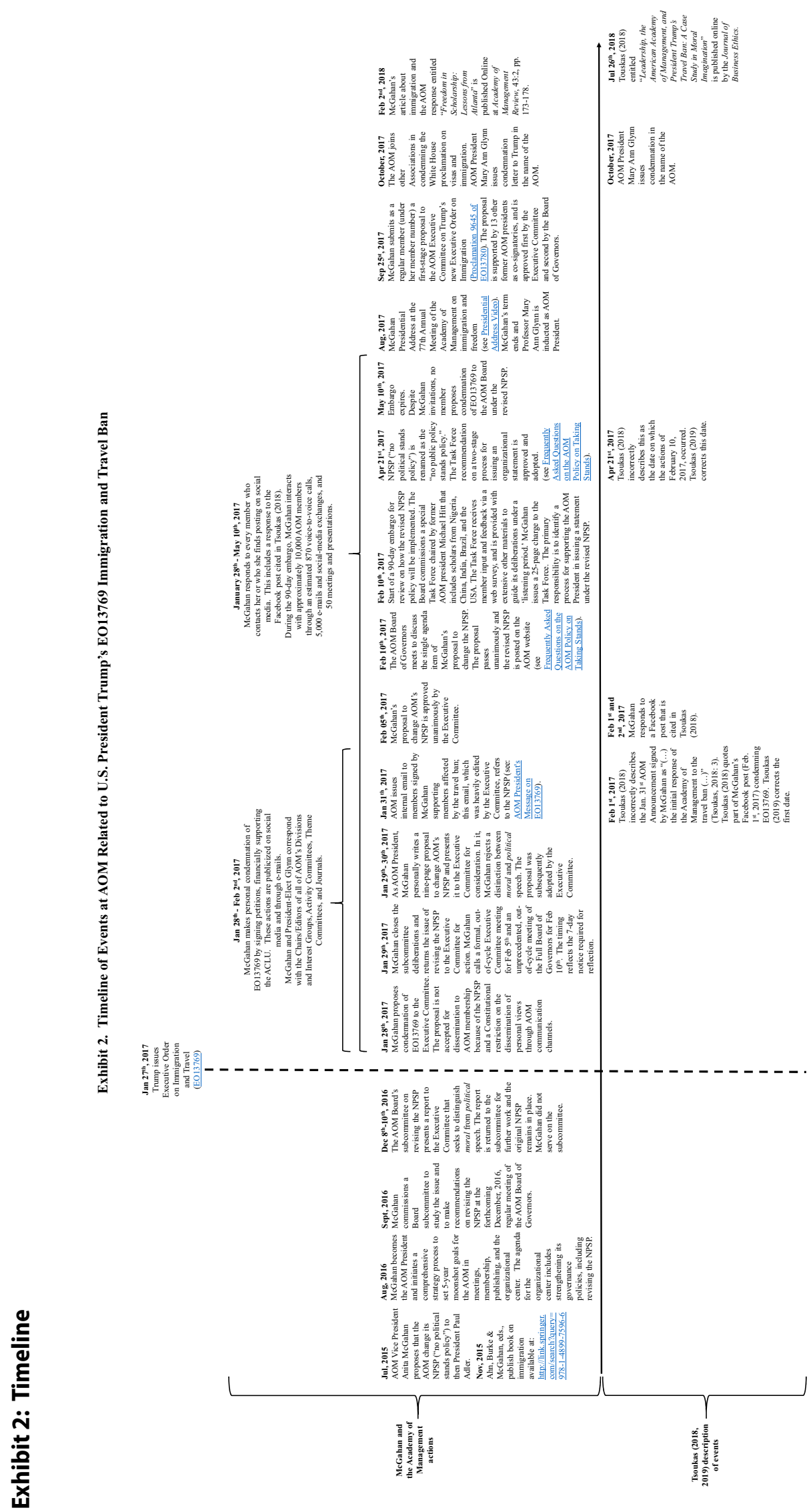




\section{Exhibit 3: Facebook posts by McGahan on February 1st and 2nd, 2017}

February 1, 2017:

In case anyone is interested: I've been quite clear where I stand personally on the Trump Executive Order: I abhor it. As the AOM President, I am restricted by a policy that binds all AOM Officers at the level of the Academy and in the Divisions. Here is the policy: I cannot represent my personal views as those of the AOM. No officer-either at the level of the AOM or in the divisions - can represent his or her views as those of the organization. Furthermore, in part because the AOM has a policy against taking political stands, it has no process by which the organization as a whole can develop and express a view. My ethics are to adhere to the policies and principles of the organization, even when I disagree with them. This stance is also a central part of the AOM Board's code of conduct. It is my fervent hope that all scholars in AOM and elsewhere double down the scholarly agenda, and that we stay intensely focused as academics on representing what is true and right.

February 1, 2017:

Anita McGahan->Haridimos Tsoukas. Thank you for this post. I've been quite clear where I stand on this as an individual: I abhor the Trump policy. I've signed petitions, given to the ACLU, and am reaching out to my colleagues and friends to offer support. As I explained yesterday, I have also been restricted by the policy that binds all AOM Officers at the level of the Academy and in the Divisions: I cannot represent my personal views as those of the AOM. Because the AOM has this policy, it has no process by which the organization as a whole can develop a coherent organizational view. In fact, we started down the road about a year ago of exploring whether and how the AOM could take a stand under extreme circumstances. As the minutes of the Board meetings show, that proposal is still in committee. In the meantime, I hope we stay unified as we need to have precisely this conversation. Best wishes, Anita McGahan

February 2, 2017:

Anita McGahan->Haridimos Tsoukas. Thank you, Prof Tsoukas. I am intent on strengthening the AOM as a scientific institution. I've posted in reply to the discussion of [X]'s comment some thoughts on these issues. The AOM is a member-driven org that does not have policies in place for supporting the expression of an org view on matters such as this. Officers cannot take stands on political policies, even when those policies also are moral in character. There are two interrelated issues here. The first is that the restriction on political speech is constraining all speech in this situation. The second is that there is no process for achieving an org view. If you believe that the AOM's governance models and policies should change, then I hope you get involved in that conversation. Best wishes

\section{References}

Ahn, R., Burke, T. F., \& McGahan, A. M. (Eds.). (2015). Innovations, urbanization and global health. New York: Springer.

Anteby, M. (2013). Manufacturing morals. Chicago: University of Chicago Press.

Arendt, H. (1982). Lectures on Kant's political philosophy. Chicago: Chicago University Press.

Arendt, H. (2003). Responsibility and judgment. New York: Schocken Books.

Bell, E., \& de Gama, N. (2019). Taking a stand: The embodied, enacted and emplaced work of relational critique. Organization, 26(6), 936-947.

Bartunek, J. M., Elsbach, K. D., Bell, E., Markides, C., Christianson, M. G., Sutcliffe, K. M., et al. (2019). Theorizing about an AOM president's response to crisis and the counter responses it evoked. Journal of Management Inquiry, 28(3), 276-282.

Caputo, J. D. (1997). Deconstruction in a Nutshell. New York: Fordham University Press.

Caputo, J. D. (2000). More radical hermeneutics. Bloomington: Indiana University Press.

Caputo, J. D. (2004). Either-or, undecidability, and two concepts of irony: Kierkegaard and Derrida. In: E. Jesgstrup, (eds.) The new kierkegaard. Bloomington: Indiana University Press.

Chappell, T. (2009). Ethics and experience: Life beyond moral theory. Durham: Acumen.

Davis, G. F., Anteby, M., Forrest Briscoe, P., Jennings, D., Karim, S., Kaul, A., et al. (2019). Politics, governance, and leadership: What can we learn from the Academy of Management's response to EO13769? Journal of Management Inquiry, 28(3), 283-290.

Derrida, J. (1992). Force of law: The mystical foundation of 'authority'. In D. Cornell, M. Rosenfield, \& D. G. Carlson (eds.) Deconstruction and the possibility of justice. London: Routledge.

Derrida, J. (1996). Remarks on deconstruction and pragmatism. In C. Mouffe (Ed.), Deconstruction and pragmatism (pp. 77-88), London: Routledge.

Derrida, J. (2002a). Negotiations. Stanford: Stanford University Press.

Derrida, J. (2002b). Acts of religion. New York: Routledge.

EO13769. (2017). Executive Order 13769, Protecting the Nation from Foreign Terrorist Entry into the United States), President of the United States of America, January 27, 2017.

Jackall, R. (1988). Moral mazes: The world of corporate managers. New York: Oxford University Press.

Johnson, M. (1993). Moral imagination: Implications of cognitive science for ethics. Chicago: University of Chicago Press.

McGahan, A. M. (2017a). Presidential address. https://www.youtu be.com/watch?v=Z4OldjLZTp8.

McGahan, A. M. (2017b). President's FAQ's on the executive order. https://aom.org/FAQExecutiveOrder.aspx.

McGahan, A. M. (2018). Freedom in scholarship: Lessons from Atlanta. Academy of Management Review, 43(2), 173-178.

McGahan, A. M. (2019). My presidency of the academy of management: Moral responsibility, leadership, governance, organizational change, and strategy. Journal of Management Inquiry, 28(3), 251-267.

McMurtrie, B. (2014). Taking political stands does not sit well with all scholarly groups. The Chronicle of Higher Education (February 17). Retrieved March 22, 2019, from https://www.chronicle.com/ article/Taking-Political-Stands-Does/144755.

Newsom, W. B. (1990). Letter to Dr. AOM Archives: Jan Beyer on AOM governance.

Nussbaum, M. C. (1999). The discernment of perception: An Aristotelian concept of private and public rationality. In N. Sherman (Ed.), Aristotle's ethics: Critical essays (pp. 145-181). Lanham: Rowman \& Littlefield Publishers. 
Pirson, M. A., Adler, P. S., Barney, J. B., Bartunek, J. M., Patient, D. L., Phillips, N., et al. (2019). From crisis to enlivenment. Journal of Management Inquiry, 28(3), 291-297.

Rasche, A. (2019). 'Speaking on behalf of...': Leadership ethics and the collective nature of moral reflection. Journal of Business Ethics. https://doi.org/10.1007/s10551-019-04325-2.

Selznick, P. (1984). Leadership in administration. Berkeley: University of California Press.

Selznick, P. (1992). The moral commonwealth. Berkeley: University of California Press.

Stackman, R. W., Martin, P., de Holan, N., Argyres, S. C., Moliterno, T. P., Stoner, J., et al. (2019). Dialogue as announced regression: $J M I$ and the case of AOM's president's response to EO13769. Journal of Management Inquiry, 28(3), 268-275.

Tsoukas, H. (2018). Leadership, the American Academy of Management, and President Trump's travel ban: A case study in moral imagination. Journal of Business Ethics, published online July 26, 2018, as https://doi.org/10.1007/s10551-018-3979-y under a Creative Commons license at https://creativecommons.org/licen ses/by/4.0/. No changes were made in the statements quoted in the article except where brackets and/or ellipses are used to identify the subjects and objects of sentences

Tsoukas, H. (2019). Correction to: Leadership, the American Academy of Management, and President Trump's Travel Ban: A case study in moral imagination. Journal of Business Ethics, published online June 25, 2019, as https://doi.org/10.1007/s10551-01904194-9 under a Creative Commons license at https://creativeco mmons.org/licenses/by/4.0/. No changes were made in the statements quoted in the article except where brackets and/or ellipses are used to identify the subjects and objects of sentences.

Yanow, D., \& Tsoukas, H. (2009). What is reflection-in-action? A phenomenological account. Journal of Management Studies, 46, 1339-1364.

Wrege, C. D. (1986). The inception, early struggles, and growth of the academy of management. Academy of Management Proceedings, $1,78-88$.

Publisher's Note Springer Nature remains neutral with regard to jurisdictional claims in published maps and institutional affiliations. 